\title{
Of saving children
}

Imre Loefler

J R Soc Med 2007; 100:110-111

Children are treated preferentially. This behaviour evolved, presumably, for it had survival value for the species. In the last sixty years, because of accelerating technological developments, special medical programs for children contributed to population increase and to demographic shifts hampering development and destroying the environment. Could it be that 'Save the Children' programs are contrary to the interests of the species? If so, would it be ethical to try to overcome the urge-wired into the genome in the form of emotions - and cease to practice positive discrimination in favour of children?

There seem to be a consensus that in the last decade or so child health and maternal health have deteriorated; WHO has renewed its concern for child and maternal health: new goals have been set by WHO itself and various other organizations.

These concerns and activities do not address the fundamental question as to why society should countenance positive discrimination in favour of children. UNICEF, the Save The Children Fund, WHO and a number of agencies and NGOs, both national and international, seem to think that somehow children are more important than adults and that one must, should, and can give preference to themand moreover that the matter is self evident.

Occasionally one encounters the argument that investments in children bring important economic rewards, and that healthy children are a prerequisite for productive adults: one should have thought that direct investment in productive adults would make more sense. The fact is that for the last fifty years, as children grew into adults, an increasing number of those adults did not find a role in the production process, had mounting difficulty in procuring essentials, and as their number, as well as the number of unproductive but consuming children, increased throughout the third world, resource depletion, environmental destruction, famines, unrest, insecurity, wars, violence and criminality increased.

The entire issue of positive discrimination in favour of children needs to be re-examined. As postmodernism is, as last, drawing to an end, political correctness can be disregarded and questions asked, questions that for decades were taboo and could not be asked.

Nairobi, Kenya

E-mail: loefler@aku.ac.ke
One question to ask is why people like children, favour children, dote on children, and are willing to make sacrifices for children. People also like small animals (puppies and kittens and all manner of pets), only to discard them when they grow up.

Concern for offspring is obviously of great survival value for any species and is part of the enormous investment individuals have to make to secure the future for their genes. Evolution saw to it that the necessary emotional triggers have been wired into all those animals which nurse, brood, feed, guard and teach their offspring, primates among them, and most outstandingly primates of the genus Homo.

The relationship of adults to children is, in the first place, emotional. This served the species well in its huntergatherer days, when life was short, maternal and child mortality was presumably very high, and the prospects of the clan depended on availability of manpower for obtaining sustenance and securing the territory. As to what the optimum age and sex composition of hunter-gatherer clans has been, we have no information, but with our knowledge of ecology we can surmise that this varied with the environment. The manpower requirements of early agricultural society were much greater and breeding became not just a matter that comes naturally but a matter of culture, of religious duty.

Eventually, with changes in technology, a situation has been created where more children have survived than required and, at the same time, the means to prevent them from being conceived became available. Except for a 'baby boom' here and there, Western society choose to settle for a reproductive strategy that barely meets replacement requirements - 'requirements' meaning that a given society believes its survival as a recognizable, more or less homogenous unit is desirable.

With the decrease in number of children, the investment in each child increased. Whether the emotional investment of Western society in its own offspring increased or not, interest in children of the third world certainly increased. Saving children has become a matter of moral obligations - and big business.

In parts of the world where child production is high, investment in children is low, and hence wastage is high. It was thought that improving survival chances will lead to 'demographic transition', as it has in Europe and eventually 
in other parts of the prosperous world. This transition has not happened at large except in the countries that are on the (economic) rise: South Korea, Hong Kong, Taiwan, Singapore and China, and to a lesser extent Brazil and India.

The saving of children has become a matter of morality — and a characteristic of postmodernism — without regard to the question of whether it retains any survival value, is economically sound and ecologically sustainable, and what the global consequences may be.

Child saving became a big industry of high moral standing and was, for a while, spectacularly successful. As the spread of child-saving technology was promoted with much more vigour than was the spread of child-preventing technology (largely because religions sprung up in early agricultural times and some still believe that breeding is a religious duty and the only excuse for sex), the world population has doubled and sub-Saharan Africa's is about to quadruple.

The invention of sexual selection accelerated evolution, hereto plodding away with natural selection; with hominification came culture, a new selection process and another acceleration of evolution, whereby Homo can invent, choose, organize - and discard - behaviours according to their survival value. Culture is an immense bag of tools, with the help of which Homo tinkers around on himself and on his environment in order to live longer and live a life of better quality, whatever that may be. At this moment in time, Homo tends to measure its success by life expectancy.

This is the evolutionary - genetic as well as culturalbackground of the urge to save children. There seems to be growing consensus that it would be better for the species if fewer children would be made. The trouble is that Rome, Washington and a voice from every minaret in the world is against 'birth control' (and the many other euphemistic labels used to refer to the technology).

To turn to questions philosophical, ethical or moral, many people think that saving children by means of positively discriminating in their favour, making enormous special investments for their sake, is primarily a moral issue.

It would be salutary if such questions would be debated dispassionately. Clearly, increasing the world's population further is not in the interest of the species. One does not need to be a Malthusian to think so. It is possible that Homo could manipulate its environment in a manner that would allow the species to attain numbers an order of magnitude greater than what we have now. Whether this is likely to happen is not the question; neither is the question whether
Homo would like to live a life that such crowding would entail — or whether anyone would like to colonise niches in the solar system made available by new technology. The problem is that the rate of population growth prevents development in many countries, and that saving children rather than preventing them being born has caused dislocations on a global scale.

The question for the ethicists to debate is whether society has the obligation to spend money on children preferentially. If one believes that ethics is essentially a system of contracts between individuals of a species gifted with the abilities of a high degree of cooperation and capable of influencing its fate by means of choices, and that culture is a collection of survival tools, it could turn out that saving children is not in the interest of the species and therefore not dictated by ethics.

It could further transpire that the imagery used to depict those children as 'innocent', and thus transmute this adjective into a purportedly self evident argument in their favour, is merely sentimental and very similar to the argument used by animal welfarists - another chief postmodernist lobby.

The ethical debate would also have to deal with the concept of 'reproductive rights'. Why should everyone have the right to breed? And if such a right can indeed be construed, what does it entail: how many children, under what circumstances, and at whose expense?

These are fundamental questions, yet they are never discussed. Central to the understanding of the conundrum is the conflict between society (the species) and the individual.

In the tradition of Western philosophy the individual is favoured. Homo, by clinging onto behaviours dictated by outdated genes and not corrected by culture, by overdoing the breeding and further amplifying its effects by child saving, and also by trying to prolong life at any cost, may have created a situation which is detrimental to the species. This could be especially true with regard to contemporary attitudes towards the beginning and the end of life.

Many of the great debates and confusions of the contemporary world, particularly of medical care, are centred on the conflict between the interests of individuals and society, the species. From abortion to euthanasia, from obtaining stem cells to in vitro fertilization, at the centre is the clash of platonic versus utilitarian ethics. So is the issue of the positive discrimination in favour of children. It would be better to remove the taboo and discuss fundamentals.

Competing interests None declared. 